\title{
Achieving adaptive ends through equivocality: A study of organizational antecedents and consequences
}

\author{
Stern Neill *, Gregory M. Rose ${ }^{1}$ \\ Milgard School of Business, University of Washington, Tacoma, 1900 Commerce Street, Tacoma, WA 98402, United States
}

\begin{abstract}
Confronting complex situations is the hallmark of strategic decision-making. While these situations may be perceived as equivocal, organizations must cope, act, and thrive within such ambiguities. This study explores the manifestation and regulation of equivocality during strategic marketing decision-making. The results indicate that organizations that tolerate ambiguity perceive greater equivocality in problem situations and exhibit greater adaptive behavior; however, the findings come with a caveat: while experienced firms may enjoy these benefits, the situation is more complex for firms with limited product-market knowledge.
\end{abstract}

Keywords: Marketing decisions; Equivocality; Innovation; Performance; Knowledge

In dynamic environments, understanding is transitory. Given the novel, complex, and indefinite nature of strategic decisions (Mintzberg et al., 1976), organizations may benefit from an open and broad interpretive capability in order to effectively model and adapt to external forces. Formulaic thinking is better suited to closed-systems where maintenance and stability are present and learning is not necessary. The challenge is in managing and remaining attuned to the equivocal inputs that manifest during strategic decision-making in information intensive environments while not succumbing to equivocality's befuddling effect. While prior studies (e.g., Day, 1994; Sinkula et al., 1997) suggest that the organization should broaden its perception and be open-minded, unresolved is the mechanism that allows for the emergence of equivocality without succumbing to its disorienting nature, which might dampen performance.

This study examines the relationship between organizational interpretation and action by capturing both the emergence and effect of equivocality during strategic marketing decisionmaking. The paper directly examines equivocality and its antecedents and consequences. Equivocality is defined as a problem situation with multiple, possibly contradictory, interpretations that manifest during decision-making (Daft and Lengel, 1986). When viewed as interpretation systems (Daft and Weick, 1984), organizations may be challenged when confronted with equivocality. Thus, several questions guide this research: 1) what are the organizational levers to equivocality and strategic change? 2) how do organizations regulate equivocality during strategic marketing decision-making? and 3) what are the consequences of equivocality? To examine these questions, we first present a conceptual framework and develop hypotheses, then describe the study method. After reporting the analyses and results, we discuss the study's findings, limitations, and implications.

\section{Conceptual framework and hypotheses}

Equivocality is "the existence of multiple and conflicting interpretations about an organizational situation." (Daft and Lengel, 1986 p. 556). The concept is distinct from that of uncertainty, which may be clarified through additional information. Rather than being a function of information quantity, equivocality is the result of an ambiguity of understanding (March and Olsen, 1976) and is due to a lack of clarity, high complexity, or a paradox that leads to more than one interpretation of environmental feedback (Martin, 1992). Consistent with this view, this study defines equivocality as the extent to which there 


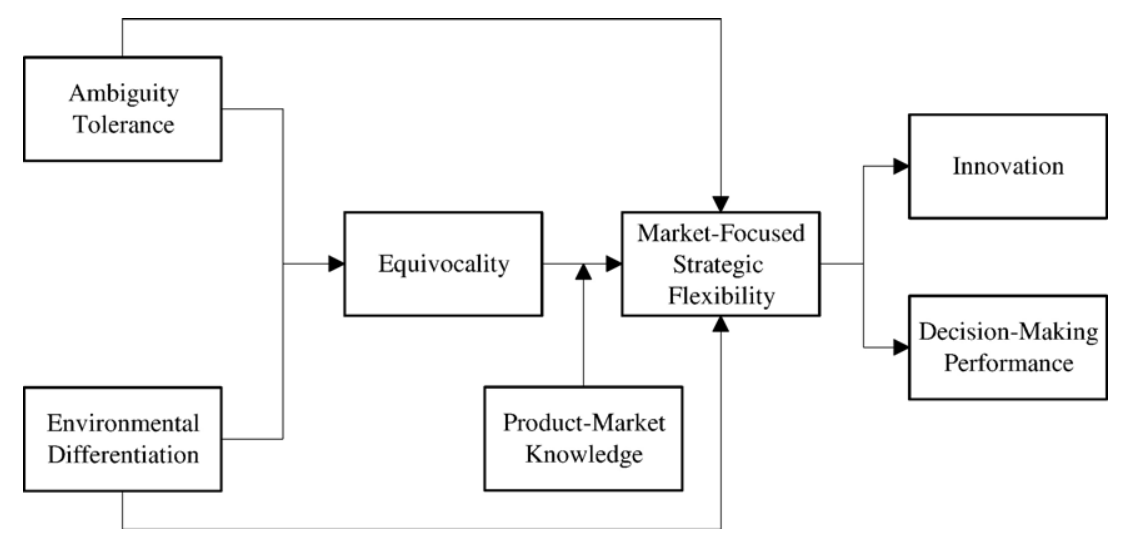

Fig. 1. Achieving adaptive ends through equivocality.

are multiple interpretations of a problem situation during decision-making.

In examining equivocality, we assume a cognitive perspective. In particular, we are interested in organizational factors that shape perceptions of equivocality and how this perception influences subsequent behaviors and outcomes. Our basic premise is that organizational tolerance and openness encourage perceptions of equivocality and strategic change behaviors, which result in innovative and enhanced outcomes. In a situation where there is an unresolved issue to be considered or solved (such as during strategic marketing decision-making), perceived equivocality generally manifests if the organization is exposed to multiple external cues. Equivocality is thus a product of openness rather than a characteristic of a single data set. While multiple studies (e.g., Deshpande and Zaltman, 1982; Low and Mohr, 2001; Menon and Varadarajan, 1992; Morgan et al., 2005; Moorman, 1995) have made important contributions to our understanding of how various factors affect market information use, far less is known about how organizations manage the equivocal situations that result from market information. And yet, several studies have observed that managers rely on equivocal information when making nonroutine decisions (Daft and Macintosh, 1981; Lee et al., 1987; Perkins and Rao, 1990). We continue this line of reasoning and argue that experience enables managers to better understand and integrate equivocal information to promote strategic change.

Sensitivity to multiple external cues creates internal disequilibrium that can encourage market-based adaptation that results in innovation and better performance. The experienced firm harnesses equivocal situations to promote innovation and performance through market-focused change. This ability to absorb equivocal inputs during strategic marketing decision-making serves as a basis for market-focused strategic flexibility, which is an organizational ability to respond to perceived market change. Prior research confirms that superior decisions are best arrived at when multiple meanings can interact rather than when differing views never surface (Schwenk, 1989; Schweiger and Sandberg, 1989; Schweiger et al., 1986). Thus, equivocality creates instability and raises questions that precipitate change.

During decision-making, equivocality manifests when ambiguity is valued and where the decision context is open to consideration of a broad set of externalities. These conditions create loose couplings among preferences, ideas, and relationships (Orton and Weick, 1990; Weick, 1976), which allow for consideration of alternative states and a reconsideration of past frameworks. As such, equivocality relaxes organizational assumptions and precedes a change in strategic objectives and resources. However, equivocality's effect on market-focused strategic flexibility is contingent on the level of product-market knowledge, which is the extent to which the organization retains memory about facts, events, or relationships concerning the product-market. With strategic flexibility comes an increased likelihood of innovation and improved performance. As outcomes of strategic marketing decision-making, innovation captures the intensity of new product introductions, while decision-making performance assesses decision-making effectiveness. Fig. 1 illustrates these relationships.

\subsection{Levers to equivocality}

This study proposes two levers to equivocality: ambiguity tolerance and environmental differentiation. Equivocality emerges through interacting inputs that flourish in an organization that values ambiguity tolerance; i.e., perceives ambiguous situations as desirable. A culture of ambiguity acknowledges indefiniteness and seeks complexity (Meyerson and Martin, 1987). The second lever concerns the organization's sensing of the environment. Environmental differentiation is the extent to which an organization uses multiple external dimensions in perceiving the environment. With environmental differentiation, the organization attunes to multiple environmental aspects and thus cannot ignore contradictory information. These organizations operate with a cognitive framework that reveals the complexities of the marketplace. Therefore, broad environmental inputs coupled with ambiguity tolerance increase equivocality during strategic marketing decisionmaking.

Hypothesis 1a. Ambiguity tolerance is positively associated with equivocality.

Hypothesis 1b. Environmental differentiation is positively associated with equivocality. 


\subsection{Levers to market-focused strategic flexibility}

Equivocality may act to liberate the organization and is indeed preferable in unstructured, less analyzable situations (Daft and Macintosh, 1981; Meyerson, 1994). Past research has demonstrated that firms can and do act in complex environments despite interpretive differences (Donnellon et al., 1986; Fiol, 1994). In fact, ambiguity may facilitate strategic change (Eisenberg, 1984; Gioia and Chittipeddi, 1991) with contradictions serving as a potential source of novel ideas and actions (Fiol, 1995).

Decisions solidify around past sensemaking efforts with future actions and interpretations conforming to this representation (Weick, 1979). This static view restricts attention to those domains that provide clarity and for which there is broad agreement (Meyerson and Martin, 1987). This adherence to prior representations serves to weaken the organization's ability to respond to shifts in the environment; whereas, equivocality serves to breakdown current thinking, decoupling it from past events and promoting adaptation. Thus, equivocality prompts market-focused strategic flexibility, which is evidenced by a reconfiguration of objectives and resources in response to a perceived market shift.

Hypothesis 2. Equivocality is positively associated with market-focused strategic flexibility.

Ashby's (1956) law of requisite variety supports the notion that to successfully adapt, one's internal variety (e.g., ideas, capabilities, knowledge,...) must equal or exceeds the complexity in one's environment. In other words, adaptive firms can handle higher levels of environmental complexity (Chakravarthy, 1982). Ambiguity tolerance and environmental differentiation create this requisite variety for strategic marketing decision-making. The ability to adapt requires a certain degree of comfort with ambiguity. Ambiguity tolerance acts as a mechanism for coping with organizational change (Judge et al., 1999). Change evokes its own ambiguity as its consequences require further interpretation that is neither certain nor static. The adaptive organization is not constrained by the ambiguities of change.

Environmental scanning is the initial step in organizational adaptation (Hambrick, 1981). However, competitive innovation demands that decision makers scan beyond the immediate task environment (i.e., channel members, competitors, and customers) to included broader trends (Dickson, 1992). A broad cognitive framework enables a greater potential range of behaviors (Fiol and Lyles, 1985; Weick, 1995), thus increasing the firm's ability to be strategically flexible (Zahra and George, 2002).

In other words, the presence and tolerance of multiple inputs promotes strategic change. Effectively navigating the boundary between the firm and its environment requires both the ability to integrate differential environmental cues and tolerate ambiguity (Dollinger, 1984). Regardless of the perception organizational members have of equivocality, having these levers in place serves to promote strategic flexibility.

Hypothesis 3a. Ambiguity tolerance is positively associated with market-focused strategic flexibility.

Hypothesis 3b. Environmental differentiation is positively associated with market-focused strategic flexibility.

\subsection{The role of product-market knowledge}

Strategic decisions often require managing equivocality. One approach is to reduce contradictions and converge on a single, common understanding from which to act (Weick, 1979). However with experience, equivocality can serve as an instrument for decision-making and creativity (Riegel, 1973). Organizational memory, of which product-market knowledge is a component, is knowledge that is stored for future decisionmaking and is necessary for effective learning (Huber, 1991). Organizational memory has been shown to increase the effectiveness of improvised actions through the recombination of prior successful experiences (Moorman and Miner, 1998a). While high memory firms may perceive decision-making contexts as structured (Berthon et al., 2001), this does not preclude such firms from also perceiving these situations as equivocal and complex.

Thus, product-market knowledge may be key in making sense of novel, complex situations (Moorman and Miner, 1998b). Under equivocal conditions and without product-market knowledge, decision makers may lack a foundation upon which to base decisions and find it difficult to understand what action if any - would be appropriate. Product-market knowledge should facilitate action by providing a frame of reference for structuring equivocality so that competing meanings can be viewed simultaneously. Organizations with such knowledge possess a developed schema allowing equivocality to serve as a foundation for change and a basis for action. Therefore, the relationship between equivocality and strategic flexibility is contingent on the level of product-market knowledge.

Hypothesis 4. The greater the product-market knowledge, the stronger the relationship between equivocality and marketfocused strategic flexibility.

\subsection{Consequences of market-focused strategic flexibility}

The essence of adaptation is the reconfiguration of organizational resources on the basis of a strategy to achieve congruence with environmental change (Chakravarthy, 1982). This principle of aligning the organization to the market is a key component of the market-driven organization (Day, 1994). Innovation is the ultimate outcome of an organization's effort to adapt to its environment; i.e., developing new forms that are ecologically optimal. This adaptive capability should be evidenced by an increased intensity of new product introductions (McKee et al., 1989). Additionally, market-focused strategic flexibility is expected to result in higher performance, particularly for firm's operating in dynamic environments (Johnson et al., 2003). Organization's that can re-configure strategic resources in the face of market shifts are better suited to pursue opportunities, thus resulting in enhanced decision-making outcomes.

Hypothesis 5a. Market-focused strategic flexibility is positively associated with innovation.

Hypothesis 5b. Market-focused strategic flexibility is positively associated with decision-making performance. 


\section{Method}

To test the hypotheses, multi-item scales were used for each of seven constructs, which are reported in the Appendix. When possible, established scales were used or adapted; however, three measures (i.e., environmental differentiation, equivocality, and market-focused strategic flexibility) were developed specifically for this study. Along with a review of the extant literature, the methodology included a pretest to assess new and adapted scales, interviews with six executives involved in strategic marketing decision-making to aid in model development, and a mail survey of business executives to assess the measures and test the hypotheses.

\subsection{Measures}

\subsubsection{Antecedent, moderator, and control measures}

Ambiguity tolerance is the degree to which the organization perceives ambiguous situations as desirable. The measure was adapted from a scale by McLain (1993). The items were adapted to reflect organizational traits. Environmental differentiation is the extent to which a decision-making unit uses multiple external dimensions in perceiving the environment. This formative measure was developed based on prior work examining individual differentiation abilities (Schroder et al., 1967) and the dimensions of an organization's marketing environment (Armstrong and Kotler, 2000). Product-market knowledge was adapted from Celly and Frazier (1996). The measure captures the extent to which the organization retains memory about facts, events, or relationships concerning the product-market and is similar to Moorman and Miner's (1997) operationalization of organizational memory for new product domains. To control for the influence of perceived environmental turbulence, we included a composite measure, used by Moorman and colleagues (2004), to gauge the level of perceived turbulence in the firm's customer, competitor and technological environments.

\subsubsection{Outcome measures}

Equivocality is the extent to which there are multiple interpretations regarding the nature of a problem situation during decision-making. The scale was developed based on the case analyses of McCaskey (1982) and research on equivocality (Daft and Lengel, 1986; Daft and Macintosh, 1981). Market-focused strategic flexibility is the organizational capability to respond to perceived market change (Johnson et al., 2003). Development of the measure was guided by prior research in strategic adaptability (McKee et al., 1989) and flexibility (Grewal and Tansuhaj, 2001). Innovation captures the organization's ability to introduce new products to the market. This measure was developed by Deshpande and colleagues (1993). Decision-making performance, as a measure of decision-making effectiveness, is adapted from a study by Moorman and colleagues (2004). The items for the study's focal construct are listed in the Appendix.

\subsection{Measurement development}

Based on conceptual definitions developed through a review of the literature, a substantial list of items was generated for the three new constructs: environmental differentiation, equivocality and market-focused strategic flexibility $(8,26$, and 18 items respectively). These items were reviewed by a panel of seven domain experts and only those items judged representative were retained. A pilot study was then undertaken to examine the internal consistency of the constructs. A sample of 40 executives considerably involved in strategic decision-making completed a web-based survey. To ensure representative respondents, informants had to engage in strategic planning within their firm. Respondents primarily held management positions $(80 \%$ were chief executive, vice president, or middle management), were considerably involved in strategic marketing decision (the sample average was 6.4 on a seven-point scale), and had an average of six or more years of experience with the organization. Each scale's unidimensionality was assessed by examining the interrelations among items using two techniques: inter-item correlations and exploratory factor analysis. Based on this procedure, the measures were trimmed and revised after ensuring that face validity would not be compromised.

\subsection{Data collection}

To test the overall model, data were gathered by surveying business executives in the bio-medical and information technology industries. These industries were chosen because firms operating in information intensive environments experience increased information processing demands that have a pronounced effect on decision processes (Glazer and Weiss, 1993). Three mailings were conducted, two letters with a questionnaire and one reminder postcard. Each respondent acted as a key informant for his/her organization by reporting on the business as a whole or in regards to the business unit in larger organizations. To be included in the study, respondents had to be involved in strategic marketing decisions. The survey was distributed to executives at 793 firms with 167 surveys returned, thus yielding a response rate of $19.3 \%$.

To assess data quality, responses were examined for key informant competency, non-response bias, data poolability, and common-methods bias. Given the requirement that each respondent be involved in strategic decisions, 14 were removed from the study. The remaining informants represented executives $(35 \%$ chief executive officer, $35 \%$ vice president, $27 \%$ middle management and $3 \%$ other) with an average of six years of experience at the organization who were involved in strategic marketing decisions to a great extent (the sample average was 6.0 on a seven-point scale). To test for non-response bias, mean differences among dependent variables were examined between early and late returns. No differences were found between these respondents on any of the dependent variables; therefore, nonresponse bias did not appear to be an issue (cf., Armstrong and Overton, 1977). To assess the appropriateness of pooling the data across the two industry groups, a Box test was performed examining the equality of covariance matrices across groups to ensure that the relationships among the dependent variables were not different. The statistic was not significant (Box's $M=5.13$, $F_{10,44987}=0.50, p=.90$ ), indicating that it is appropriate to combine the sample. To test for common methods bias, a Harman's one- 
Table 1

Measurement model results

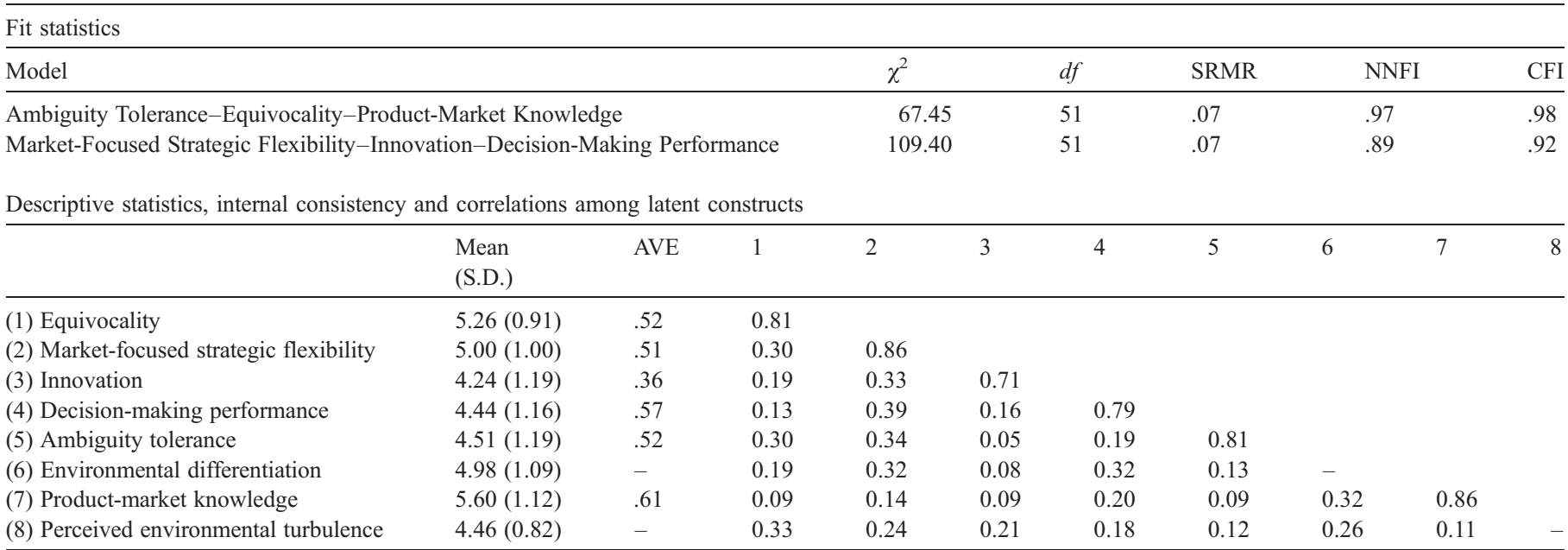

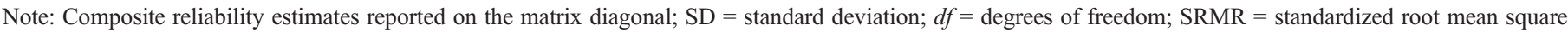
residual; $\mathrm{NNFI}=$ non-normed fit index; $\mathrm{CFI}=$ comparative fit index.

factor test was performed (cf., Jayachandran and Varadarajan, 2006; Podsakoff and Organ, 1986). The test did not indicate a common source of variance, as the factor structure is confirmed with the first factor accounting for $23 \%$ of the variance.

\section{Results}

\subsection{Measurement results}

The item distribution and factor loadings of individual factors were initially examined and were deemed acceptable. Next, the constructs were modeled as first-order factors in LISREL VIII using the covariance matrix as input. This allowed for examination of both within- and across-factor loadings and measurement error. Given the limited sample size, the factors were modeled in two related sets. Table 1 presents measurement model fit indices for the two related sets of constructs, along with summary statistics, internal consistency estimates, and correlations.

The measurement model results indicate that the estimated model adequately represents the observed input matrix (i.e., covariance matrix) for the two sets of constructs. As evidence of internal consistency, both composite reliability and average variance extracted (AVE) estimates are within acceptable ranges, except for the innovation construct (cf., Netemeyer et al., 2003). Additional tests also confirmed that each constructs possessed discriminant validity. More specifically, the most stringent test was performed to ensure that distinct constructs were being measured, by ensuring that the square of the parameter estimate between two constructs $\left(\phi^{2}\right)$ is less than the average AVE between any two constructs (Fornell and Larcker, 1981).

\subsection{Structural model results}

To test the structural model, the correlation matrix, based on an average of the scale indicators, was used as input. To control for measurement error, each loading estimate was fixed as the square root of the reliability estimate, and the error term was set to one minus the reliability (Hair et al., 2006). Perceived environmental turbulence was also included in the analysis to control its effect on the outcome variables. Given environmental differentiation and

Table 2

Structural model results

\begin{tabular}{lllll}
\hline Fit statistics & & & & \\
\hline$\chi^{2}$ & $d f$ & SRMR & NNFI & CFI \\
\hline 9.95 & 7 & .04 & .93 & .98
\end{tabular}

Explained variance in endogenous constructs

\begin{tabular}{|c|c|c|c|}
\hline Endogenous constructs & \multicolumn{3}{|c|}{ Explained variance } \\
\hline Equivocality & \multicolumn{3}{|l|}{.26} \\
\hline Market-focused strategic flexibility & \multicolumn{3}{|l|}{.32} \\
\hline Innovation & \multicolumn{3}{|l|}{.21} \\
\hline Decision-making performance & \multicolumn{3}{|l|}{.24} \\
\hline \multicolumn{4}{|l|}{ Completely standardized path estimates } \\
\hline Hypotheses: path & & \multicolumn{2}{|c|}{$\begin{array}{l}\text { Estimate } \\
\text { (T-value) }\end{array}$} \\
\hline $\mathrm{H}_{1 \mathrm{a}}$ : Ambiguity Tolerance $\rightarrow$ Equivocality & & .27 & $(2.90)$ \\
\hline $\mathrm{H}_{1 \mathrm{~b}}$ : Environmental Differentiation $\rightarrow$ Equivocality & & .12 & $(1.15)$ \\
\hline $\mathrm{H}_{2}$ : Equivocality $\rightarrow$ Market-Focused Strategic Flexibility & & .21 & $(2.05)$ \\
\hline $\begin{array}{l}\mathrm{H}_{3 \mathrm{a}}: \text { Ambiguity Tolerance } \rightarrow \text { Market-Focused } \\
\text { Strategic Flexibility }\end{array}$ & & .23 & $(2.43)$ \\
\hline $\begin{array}{l}\mathrm{H}_{3 \mathrm{~b}} \text { : Environmental Differentiation } \rightarrow \text { Market-Focused } \\
\text { Strategic Flexibility }\end{array}$ & & .30 & $(3.18)$ \\
\hline $\mathrm{H}_{5 \mathrm{a}}:$ Market-Focused Strategic Flexibility $\rightarrow$ Innovation & & .38 & $(3.63)$ \\
\hline $\begin{array}{l}\mathrm{H}_{5 \mathrm{~b}}: \text { Market-Focused Strategic Flexibility } \rightarrow \text { Decision-M } \\
\text { Performance }\end{array}$ & & .45 & $(4.62)$ \\
\hline
\end{tabular}

Performance

Control variable paths

Estimate (T-value)

Perceived Environmental Turbulence $\rightarrow$ Equivocality

Perceived Environmental Turbulence $\rightarrow$ Market-Focused

$.07 \quad(0.72)$

Strategic Flexibility

Perceived Environmental Turbulence $\rightarrow$ Innovation

$.18 \quad(1.65)$

Perceived Environmental Turbulence $\rightarrow$ Decision-Making

$11(1.05)$ Performance

Note: $T$-values (in parentheses) of 1.65 or greater are significant at the .05 level; $t$-values of 2.33 or greater are significant at the .01 level. 
perceived environmental turbulence were formative measures that combine distinct elements of a construct, a reliability of .80 was assumed and the error term was fixed at .20 (Hair et al., 2006). The structural model results are presented in Table 2. The overall fit of the structural model was adequate. Six of seven paths are statistically significant ( $p<.05$ or better) and account for twenty percent or more of the variance in each endogenous variable.

To test for moderation, a multi-group analysis was conducted for both low and high levels of product-market knowledge, based on two groups formed using cluster analysis (cf., Hair et al., 2006). The fit of the model with all hypothesized parameter estimates estimated freely was acceptable $\left(\chi^{2}=14.76\right.$ with $14 d . f$; $\quad$ SRMR $=.04$; $\mathrm{NNFI}=.98 ; \mathrm{CFI}=.99$ ). The model was then re-estimated with the path between equivocality and market-focused strategic flexibility constrained to equality between the low product-market knowledge group and the high product-market knowledge group. The model fit was considerably worse $\left(\chi^{2}=26.44\right.$ with $15 d$.f; $\quad \operatorname{SRMR}=.06$; $\mathrm{NNFI}=.73 ; \mathrm{CFI}=.90)$; and a chi-square difference test indicated that the relationship between equivocality and market-focused strategic flexibility differed between the low and high productknowledge groups $\left(\chi_{\text {diff }}^{2}=11.68\right.$ with $\left.1 d . f_{\text {.diff, }} p<.01\right)$.

\subsection{Hypotheses tests}

Hypothesis $1 \mathrm{a}$ and $1 \mathrm{~b}$ proposed that both ambiguity tolerance and environmental differentiation share a positive relationship with equivocality; however, the results supported the former $\left(\mathrm{H}_{1 \mathrm{a}}\right.$; $\gamma=.27, p<.01)$ and not the latter $\left(\mathrm{H}_{1 \mathrm{~b}} ; \gamma=.12, p>.05\right)$ relationship. Although the latter relationship was not significant, the path was both significant and positive in the absence of the control variable. In support of Hypothesis 2, equivocality is related to market-focused strategic flexibility $(\beta=.21, p<.05)$. Ambiguity tolerance and environmental differentiation are positively related to market-focused strategic flexibility in support of $\mathrm{H}_{3 \mathrm{a}}(\gamma=.23, p<.01)$ and $\mathrm{H}_{3 \mathrm{~b}}(\gamma=.30, p<.01)$, respectively. Recall that Hypothesis 4 posited that product-market knowledge moderates the relationship between equivocality and marketfocused strategic flexibility and that a chi-square difference test supported this moderation. Examining this relationship across groups offers additional support in that the relationship is significantly negative in the low product-knowledge group ( $\beta=$ $-.24, p<.05)$, while in the high knowledge group the path is significantly positive $(\beta=.52, p<.01)$. Finally, market-focused strategic flexibility is positively related to both innovation $(\beta=.38, p<.01)$ and decision-making performance $(\beta=.45$, $p<.01$ ), supporting hypotheses $5_{\mathrm{a}}$ and $5_{\mathrm{b}}$, respectively.

\section{Discussion}

The results of this study provide an examination of how organizations manage equivocality during strategic marketing decision-making. Equivocality presents a unique framework for understanding decision-making. Rather than seeking equilibrium and stability, firms may embrace equivocality as an instrument of change by exposing the firm to multiple interpretations that serve to both expand and relax current thinking and practice. In examining equivocality, this study has provided a test of the notion of 'ambiguity-by-design' as a means for initiating change efforts (Gioia and Chittipeddi, 1991).

However, the nature of the relationship between equivocality and market-focused strategic flexibility is contingent on the level of product-market knowledge. This finding extends our understanding of the role of organizational memory. While prior research positions memory as a core rigidity that leads to selective attention and restricts learning and adaptation (Leonard-Barton, 1992; Sinkula, 1994; Slater and Narver, 1995; Walsh and Ungson, 1991), our results present a different picture. Rather than being bogged down by memory, this study demonstrates that productmarket knowledge allows equivocality to serve as a means for change, releasing the firm from single-loop learning that reinforces the status quo (Argyris and Schon, 1978). In this way, adaptive firms are viewed as a product of managing equivocality through memory.

Strategic marketing decisions involve complex issues that demand an open and differentiated cognitive framework in order to effectively understand and respond to problem situations. The results indicate that ambiguity tolerance increases market-focused strategic flexibility both directly and indirectly through its relationship with equivocality. Environmental differentiation is positively related to market-focused strategic flexibility but is not significantly related to equivocality after controlling for the effects of environmental turbulence. Controlling for environmental turbulence suppresses the relationship between environmental differentiation and equivocality, indicating that turbulence in the environment is related to and possibly influences the assessment of multiple dimensions. Nonetheless, both ambiguity tolerance and environmental differentiation expose strategic decisions to options that enable the firm to reconfigure strategic resources in response to marketplace change.

Further, the results support that market-focused strategic flexibility functions as an organizational capability in that it entails the firm's ability to effectively configure resources to better respond in a changing environment (Eisenhardt and Martin, 2000; Johnson et al., 2003). As such, it is important to understand the internal mechanisms that promote it. Based on this study's results, market-based strategic flexibility is stimulated by equivocality, ambiguity tolerance and environmental differentiation. As demonstrated here, strategic flexibility promotes innovation and improves decision-making performance, thereby contributing to a sustainable competitive advantage.

\subsection{Limitations and opportunities for future research}

This study has limitations that should be considered when interpreting the findings. The cross-sectional design limits claims of causality. Additionally, the sample was drawn from single informants from firms operating in information intensive industries. Given that prior research has demonstrated consistent results when analyzing a single informant versus aggregating group perceptions (Atuahene-Gima and Murray, 2004; Miller et al., 1998), the use of competent informants should provide tenable results. The use of single-industries may limit the generalizabilty of the findings; however, it does allow for control of industry-related effects while providing a robust test of the 
theory. The findings concerning innovation should be tempered due to measurement issues. Although this measure appears to be internally consistent and its relationship to strategic flexibility was significant, a better measure is warranted.

This study does not address the inherent tensions between ambiguity and explicitness. As the results indicate, equivocality is beneficial during strategic decision-making; however, consensus may be required during implementation when coordination is needed. In other words, strategic flexibility may benefit from multiple interpretations, but effective implementation may require convergence once strategic resources are allocated in response to a market shift. Fiol (1994), however, demonstrates that unification that maintains a diversity of interpretations can be achieved through a broad framing of the issues. Framing provides the "landscape" for strategic decisions (Nutt, 1998). Our results demonstrate that product-market knowledge may provide this unifying effect by providing a schema for managing equivocality. Future research might continue to examine the extent to which framing and knowledge shape strategic decisionmaking and provide a degree of coordination while maintaining requisite variety during interpretation.

Interpretations have a profound effect on firm behavior (Barr, 1998); as such, a fruitful area of research would examine prevailing perceptions on strategic marketing decision-making. For example, this study neither examines the content of these efforts nor considers scanning of internal capabilities. Garg et al. (2003) provide evidence that in dynamic environments, adaptive firms simultaneously scan the immediate task section (customers, competitors, and technology) including internal organizational capabilities associated with innovation in order to achieve congruence. Clearly, explanations are needed as to the activation triggers relating to attention (Ocasio, 1997), enactment (Weick, 1979, 1995) and noticing (Starbuck and Milliken, 1988), particularly as these triggers relate to shifting executive focus towards sources of innovation and change.

\subsection{Implications for managers}

Decision-making that focuses on what is known or knowable (e.g., existing customers, technologies, and/or strategies) are less ambiguous. A single interpretation (e.g., of who the firm's customer is) encourages a stay-the-course posture rather than promoting innovation and success. In stable environments, firms may benefit from maintaining a singular view that offers consistency and sustains current strategies. However, dynamic markets require organizations to rethink prevailing paradigms in order to promote such change that drives innovation and performance. Thus, adaptation to external change requires that the firm open up and permit equivocality. The results of this study provide managers with direction as to the specific mechanisms that regulate equivocality and enable adaptation in dynamic environments.

As Christensen and Bower (1996) discovered in their historical analysis of the disk drive industry, failure to manage innovation is due to an inability to change strategy rather than technology. In dynamic environments, success requires managing innovation "in a manner that is out of organizational and strategic context" (p. 215). Our study indicates two important mechanisms for achieving this: environmental differentiation and ambiguity tolerance. For experienced firms, equivocality promotes strategic flexibility, while firms with less productmarket knowledge find equivocality to be an obstacle.

Traditionally, coping with equivocality entails simplification (Schwenk, 1984) or avoidance (March and Olsen, 1976). As Berthon et al. (1999) suggest, firms in stable environments may choose an isolationist mode by focusing inward and closing the organization to external forces; however, this comes at a cost as reducing equivocality through simplification or reductionism may promote inertia and tunnel vision making the organization less responsive in a dynamic environment. However for organizations with limited product-market knowledge, it may be functional, at least temporarily, to engage in reductionism; yet, this presents a paradox in that such firms may not learn and adapt.

\section{Conclusion}

This study offers further insight into the relationship between organizational interpretation and behavior (Daft and Weick, 1984). The common wisdom is that an adaptive organization draws on the richness of its external links through openness and diversity; however, this view does not consider the interpretive load this places on strategic decision-making. Additionally negative connotations of ambiguity are generally accepted at face value; and yet, there are benefits to be derived from equivocal states. This study adds structure to this debate by examining how the organization manages equivocality as a means of adaptation.

\section{Appendix A. Focal construct measures}

\section{Equivocality ${ }^{1}$}

Generally when engaged in strategic marketing decisionmaking,...

there are multiple interpretations of market feedback

the issues are open to multiple interpretations individuals focus on different issues

the situation is viewed from different perspectives

\section{Market-focused strategic flexibility ${ }^{1}$}

With a shift in the marketplace, this organization generally... reconfigures investments in response.

modifies priorities with changing conditions.

shifts its strategic focus based on new information.

takes action in response to environmental changes.

reallocates resources in response to the change.

develops new capabilities in response to environmental shifts.

\section{Innovation $^{2}$}

In a new product/service introduction, how often is your organization...

first-to-market with new products and services.

a later entrant in established but still growing markets. (r)*

an entrant in mature, stable markets. (r) 
at the cutting edge of technological innovation.

an entrant in declining markets. (r)*

\section{Decision-making performance ${ }^{3}$}

Relative to your stated objectives, how is your organization performing on...

financial performance of strategic marketing decisions. speed of strategic marketing decision-making. creativity of strategic marketing decisions.

\section{Product-Market Knowledge ${ }^{1}$}

When it comes to our product-market, this organization...

is very familiar.

has excellent knowledge.

has a good understanding.

has a great deal of experience.

\section{Ambiguity Tolerance ${ }^{1}$}

When engaged in strategic marketing decision-making, this organization generally ...

is tolerant of ambiguous situations

is good at managing unpredictable situations

tolerates ambiguous situations well

is drawn to situations which can be interpreted in more than one way

\section{Environmental Differentiation ${ }^{2}$}

During strategic marketing decision-making, to what extent does your unit consider or seek information about ... channel members (e.g., suppliers, distributors, or retailers). competitors.

customers.

economic conditions.

legal, regulatory, or political conditions.

social, cultural, or demographic conditions.

technological conditions.

${ }^{1}$ Seven-point agree-disagree scale.

${ }^{2}$ Seven-point never-always scale.

${ }^{3}$ Seven-point worse-better scale.

(r) Reverse coded.

* Removed.

\section{References}

Argyris C, Schon DA. Organizational Learning: A Theory of Action Perspective. Reading, MA: Addison-Wesley; 1978.

Armstrong G, Kotler P. Marketing: An Introduction. 5th ed. Upper Saddle River, NJ: Prentice Hall; 2000.

Armstrong JS, Overton TS. Estimating Nonresponse Bias in Mail Surveys. J Mark Res 1977;14(1):396-402.

Ashby WR. An Introduction to Cybernetics. London: Chapman and Hall; 1956.

Atuahene-Gima K, Murray JY. Antecedents and outcomes of marketing strategy comprehensiveness. J Mark 2004;68(4):33-46.

Barr PS. Adapting to unfamiliar environmental events: a look at the evolution of interpretation and its role in strategic change. Organ Sci 1998;9(6):644-69.

Berthon P, Hulbert JM, Pitt LF. To serve or create? Strategic orientations toward customers and innovation. Calif Manage Rev 1999;42(1):37-58.
Berthon P, Pitt LF, Ewing MT. Corollaries of the collective: the influence of organizational culture and memory development on perceived decisionmaking context. J Acad Mark Sci 2001;29(2):135-50.

Celly KS, Frazier GL. Outcome-based and behavior-based coordination efforts in channel relationships. J Mark Res 1996;33(2):200-10.

Chakravarthy BS. Adaptation: a promising metaphor for strategic management Acad Manage Rev 1982;7(1):35-44.

Christensen CM, Bower JL. Customer power, strategic investment, and the failure of leading firms. Strateg Manage J 1996;17:197-218.

Daft RL, Lengel RH. Organizational information requirements, media richness, and structural design. Manage Sci 1986;32:554-71.

Daft RL, Macintosh NB. A tentative exploration into the amount and equivocality of information processing in organizational work units. Adm Sci Q 1981;26:207-24.

Daft RL, Weick KE. Toward a model of organizations as interpretation systems. Acad Manage Rev 1984;9(2):284-95.

Day GS. The capabilities of market-driven organizations. J Mark 1994;58(4):37-52.

Deshpande R, Zaltman G. Factors affecting the use of market research information: a path analysis. J Mark Res 1982;19(1):14-31.

Deshpande R, Farley JU, Webster FE. Corporate culture, customer orientations, and innovativeness in Japanese firms: a quadrad analysis. J Mark 1993;57(1):23-36.

Dickson PR. Toward a general theory of competitive rationality. J Mark 1992;56 (1):69-83.

Dollinger MJ. Environmental boundary spanning and information processing effects on organizational performance. Acad Manage J 1984;27(2):351-68.

Donnellon A, Gray B, Bougon MG. Communication, meaning, and organized action. Adm Sci Q 1986;31:43-55.

Eisenberg EM. Ambiguity as srategy in organizational communication. Commun Monogr 1984;51:227-42.

Eisenhardt KM, Martin JA. Dynamic capabilities: what are they? Strateg Manage J 2000;21:1105-21.

Fiol CM. Consensus, diversity, and learning in organizations. Organ Sci 1994;5 (3):403-20.

Fiol CM. Thought worlds colliding: the role of contradiction in corporate innovation processes. Entrep Theory Pract 1995;19(3):71-90.

Fiol CM, Lyles MA. Organizational learning. Acad Manage Rev 1985;10 (4):803-13.

Fornell C, Larcker DF. Evaluating structural equation models with unobservable variables and measurement error. J Mark Res 1981;18(1):39-50.

Garg VK, Walters BA, Priem RL. Chief executive scanning emphases, environmental dynamism, and manufacturing firm performance. Strateg Manage J 2003;24(8):725-44.

Gioia DA, Chittipeddi K. Sensemaking and sensegiving in strategic change initiation. Strateg Manage J 1991;12:433-48.

Glazer R, Weiss AM. Marketing in turbulent environments: decision processes and the time-sensitivity of information. J Mark Res 1993;30(4):509-21.

Grewal R, Tansuhaj P. Building organizational capabilities for managing economic crisis: the role of market orientation and strategic flexibility. J Mark 2001;65:67-80 [April].

Hair JF, Black WC, Babin BJ, Anderson RE, Tatham RL. Multivariate Data Analysis, 6/e. Upper Saddle River, NJ: Pearson Prentice Hall; 2006.

Hambrick DC. Specialization of environmental scanning activities among upper level executives. J Manag Stud 1981;18(3):299-20.

Huber GP. Organizational learning: the contributing processes and the literatures. Organ Sci 1991;2(1):88-115.

Jayachandran S, Varadarajan R. Does success diminish competitive responsiveness? Reconciling conflicting perspectives. J Acad Mark Sci 2006;34 (3):284-94.

Johnson JL, Lee RP, Saini A, Grohmann B. Market-focused strategic flexibility: conceptual advances and an integrative model. J Acad Mark Sci 2003;31 (1):74-89.

Judge TA, Thoresen CJ, Pucik V, Welbourne TM. Managerial coping with organizational change: a dispositional perspective. J Appl Psychol 1999;84 (1): $107-22$.

Lee H, Acito F, Day RL. Evaluation and use of marketing research by decision makers: a behavioral simulation. J Mark Res 1987;24(2):187-96.

Leonard-Barton D. Core capabilities and core rigidities: a paradox in managing new product development. Strateg Manage J 1992;13:111-25. 
Low GS, Mohr JJ. Factors affecting the use of information in the evaluation of marketing communications productivity. J Acad Mark Sci 2001;29 (1):70-88

March JG, Olsen JP. Organizational Choice Under Ambiguity. In: March JG, Olsen JP, editors. Ambiguity and Choice in Organizations. 2nd ed. Bergen, Norway: Universitetsforlaget; 1976. p. 10-23.

Martin J. Cultures in Organizations: Three Perspectives. New York: Oxford University; 1992.

McCaskey MB. The Executive Challenge: Managing Change and Ambiguity. Boston: Pitman; 1982

McKee DO, Varadarajan PR, Pride WM. Strategic adaptability and firm performance: a market-contingent perspective. J Mark 1989;53:21-35 [July].

McLain DL. The MSTAT-I: a new measure of an individual's tolerance for ambiguity. Educ Psychol Meas 1993;53:183-9.

Menon A, Varadarajan PR. A model of marketing knowledge use within firms. J Mark 1992;56(4):53-71.

Meyerson DE. Interpretations of stress in institutions: the cultural production of ambiguity and burnout. Adm Sci Q 1994;39:628-53.

Meyerson DE, Martin J. Cultural change: an integration of three different views. J Manag Stud 1987;24(6):623-47.

Miller CC, Burke LM, Glick WH. Cognitive diversity among upper-echelon executives: implications for strategic decision processes. Strateg Manage J 1998;19:39-58.

Mintzberg H, Raisinghani D, Theoret A. The structure of 'unstructured' decision processes. Adm Sci Q 1976;21:246-75.

Moorman C. Organizational market information processes: cultural antecedents and new product outcomes. J Mark Res 1995;32:318-35 [August].

Moorman C, Miner AS. The impact of organizational memory on new product performance and creativity. J Mark Res 1997;34(1):91-106.

Moorman C, Miner AS. The convergence of planning and execution: improvisation in new product development. J Mark 1998a;62(3):1-20.

Moorman C, Miner AS. Organizational improvisation and organizational memory. Acad Manage Rev 1998b;23(4):698-723.

Moorman C, Rust RT, Dickson PR. The Managerial Path to Return on Quality: How Individual and Collective Belief Systems Evolve in the Firm. Market Science Institute Reports, vol. 04-107; 2004.

Morgan NA, Anderson EW, Mittal V. Understanding firms' customer satisfaction information usage. J Mark 2005;69(3):131-51.

Netemeyer RG, Bearden WO, Sharma S. Scaling Procedures: Issues and Applications. Thousand Oaks, CA: Sage Publications; 2003.

Nutt PC. Framing strategic decisions. Organ Sci 1998;9(2):195-216.
Ocasio W. Towards an attention-based view of the firm. Strateg Manage J 1997;18:187-206 [Summer Special Issue].

Orton JD, Weick KE. Loosely coupled systems: a reconceptualization. Acad Manage Rev 1990;15(2):203-23.

Perkins WS, Rao RC. The role of experience in information use and decision making by marketing managers. J Mark Res 1990;27(1):1-10.

Podsakoff PM, Organ DW. Self-reports in organizational research: problems and prospects. J Manage 1986;12:531-44.

Riegel KF. Dialectical operations: the final period of cognitive development. Hum Dev 1973;16:346-70.

Schroder HM, Driver MJ, Streufert S. Human Information Processing. New York: Holt, Rinehart, and Winston, Inc.; 1967.

Schweiger DM, Sandberg WR. The utilization of individual capabilities in group approaches to strategic decision-making. Strateg Manage J 1989;10 (1):31-43.

Schweiger DM, Sandberg WR, Ragan JW. Group approaches for improving strategic decision making: a comparative analysis of dialectical inquiry, devil's advocacy, and consensus. Acad Manage J 1986;29(1):51-71.

Schwenk CR. Cognitive simplification processes in decision-making. Strateg Manage J 1984;5:111-28.

Schwenk CR. A meta-analysis on the comparative effectiveness of devil's advocacy and dialectical inquiry. Strateg Manage J 1989;10(3):303-6.

Sinkula JM. Marketing information processing and organizational learning. J Mark 1994;58:35-45 [January].

Sinkula JM, Baker WE, Noordewier T. A framework for market-based organizational learning: linking values, knowledge, and behavior. J Acad Mark Sci 1997;25(4):305-31.

Slater SF, Narver JC. Market orientation and the learning orientation. J Mark 1995;59(3):63-74.

Starbuck WH, Milliken FJ. Executives' perceptual filters: what they notice and how they make sense. In: Hambrick DC, editor. The Executive Effect: Concepts for Studying Top Managers. Greenwich, CT: JAI Press; 1988. p. 35-65.

Walsh JP, Ungson GR. Organizational memory. Acad Manage Rev 1991;16 (1):57-91.

Weick KE. Educational organizations as loosely coupled systems. Adm Sci Q 1976;21:211-9.

Weick KE. The Social Psychology of Organizing. 2nd ed. NewYork: McGrawHill; 1979.

Weick KE. Sensemaking in Organizations. Thousand Oaks: Sage; 1995.

Zahra SA, George G. Absorptive capacity: a review, reconceptualization, and extension. Acad Manage 2002;27(2):185-203. 